Proceedings

\title{
On the Game Relations between Human and Big Data-Based Machines in the Information Ecology ${ }^{\dagger}$
}

\author{
Dazhou Wang \\ School of Humanities and Social Sciences, University of Chinese Academy of Sciences, Beijing 100049, China; \\ dzwang@ucas.ac.cn; Tel.: +86-10-88256360 \\ + Presented at the IS4SI 2017 Summit DIGITALISATION FOR A SUSTAINABLE SOCIETY, Gothenburg, \\ Sweden, 12-16 June 2017.
}

Published: 8 June 2017

\begin{abstract}
As a new type of machines, the big data-based machine, which may be called the ubiquitous machines, is qualitatively different from the traditional one. The purpose of this paper is to look beyond traditional understanding of human-machine relations and focus on the real challenge brought by the big data based machines in the context of information ecology.
\end{abstract}

Keywords: information ecology; big data-based machine; game relation; artificial intelligence; re-intelligentization of human being

\section{Introduction}

Big data is a term for data sets that are so large that traditional data processing software is incapable to cope with them. The term big data often refers to the use of predictive analytics, user behavior analytics, or certain other advanced data analytics methods that attract valuable information from data. With the emergence of big data analytics, a new type of machines, may be called the big data-based machine or the ubiquitous computing machines, has emerged following the big data analytics. It is qualitatively different from the traditional one in terms of human-machine relations. The purpose of this paper is to look beyond traditional understanding of human-machine relation and to focus on the real challenge brought by big data based intelligent machines in the context of information ecology.

\section{On Ihde's Four Relations between Human and Artifacts}

In order to do this, it would be better to start from the concept of human-artifact relations as developed by American philosopher Don Ihde in his book Technology and the Lifeworld: From Garden to Earth [1]. According to Ihde, there are four typical relations between human and artifacts, i.e., embodiment relation, hermeneutic relation, alterity relation and background relation. Embodiment relation is characterized by a "partial symbiosis" of a person and an artifact during which the artifact in use is "embodied" and becomes "perceptually transparent". Hermeneutic relation involves interpretation of the world mediated by an artifact. Although one might be focused on the artifact, what one actually sees is not the artifact itself but rather the world it refers to. The third type of relations, alterity relation, means that the artifact is experienced as a "quasi-other", and an example would be an intelligent robot. Difference from the above-mentioned three relations involving artifacts that require direct and focal attention, the final type, background relation, is located at the periphery of human attention. Such a relation is understood as "present absence", as something not directly experienced although giving structure to direct experiences. For example, an automated home air-conditioning system does not require any special attention, however, it continues to shape the inhabitants' experience by providing a pleasantly cool environment. 
Although Ihde's analysis has huge strength in understand of the mediating role played by artifacts, its shortcoming is also obvious. In fact, Ihde focuses mainly on the relations between a single artifact and its user [2], and the "world" in his analysis seems to be a pure "black box". He considers neither the relations between the artifact and non-users who are affected by the artifact, nor the position of such an artifact and its users, let alone other actors, within the information ecology, defined as a system of people, practices, technologies, and values in a local environment [3-5]. Moreover, as a pragmatic phenomenologist/philosopher, surprisingly he cares little about the pragmatic value of his analysis.

\section{On Relations between Human and Big Data-Based Machines}

In face of the big data-based machines, it might be interesting what Ihde would clarify them in terms of the human-artifact relations. Of the four relations, the background relation seems to be a choice, for such machines are located at the periphery of human attention and the relation between human and machines can be understood as "present absence". I argue, however, that the big data-based machines have brought a special kind of human-artifact relations within the information ecology. For those people to be surveilled and interpreted by big data based machines, the human-machine relationship is no longer the background relation in Ihde's sense, rather, it is the "inverted" hermeneutic relation, in which people become the data source and objects of interpretation and even of controlling.

This situation will trigger such a drastic game of interpreting and anti-interpreting that may function as the intrinsic dynamics of evolution of the information ecology. On one hand, the users of the big-data machines are trying to get more and more data, be it sensitive or insensitive, from any source, and even trying to surveille and reconstruct the net-self of human as object. On the other hand, the surveilled human has to elude such intrusion and harassment. Currently, researchers and companies all over the world pay their attention much more on the former aspect rather than the latter one. Given that there are also business opportunities in the anti-surveillance/control enterprise, new alliances may be formed between the surveilled human being and big data researches and companies. As a result, the focus of the interface design will shift in some degree to the human side in order to meet their demands of newly technological armors, which marks the re-intelligentization of the human being. Among which, using smart technology to camouflage themselves, i.e., to prevent big data based machines from precise reconstruction of their online self, will be an important aspect. For that matter, the challenge of big data and artificial intelligence, is not so much the question of whether or not the artificial intelligence will surpass human being [6], as to how to make use of it to upgrade human intelligence in order that human being can adapt to the intelligentized information ecology better. In this sense, the intelligent information ecology will be a new battlefield, where human is becoming the commanding height. The mangle between the alliance of researchers and companies who safeguard humanities and that of researchers and companies who utilized human being as resources can be fierce.

In reality, the game relations between human and the big data-based machines results in the property exchange between them. The big data machines would be more and more humanized in terms of its intelligent character, and in the meantime human would be more and more technologized in term of re-intelligentazation. From the perspective of experimental philosophy of engineering, what we need is experimental spirits by which human being can enter into the self-transforming evolutionary process. Generally speaking, human beings have experienced two stages of evolution: evolution in vivo and evolution in vitro. With the emergence of more and more advanced technologies such as biological technology and artificial intelligence, however, neo-evolution in vivo has begun to reappear and accelerate. Such new technologies can be used to enhance human beings up to unprecedented higher level. In fact, the integration of AI technologies and the individual users has become an emerging area [7], p. 137.

With this kind of possibilities, the post-humanist endeavor seems to be inevitable [8]. The proverb "know thyself" shall be re-asked as "re-create thyself". Certainly, how to design the experiment spaces to accommodate such a re-creation process will be the critical issue in the first 
place. In so doing, we should also recreate the information ecology so as to accommodate ourselves better.

\section{Conclusions}

The big data-based machine is rather different from the traditional one in terms of human-machine relations. Ihde's post-phenomenology analysis should be extended to include the inverted hermeneutic relation between human and the big data based machines. The game relations between human and the big data-based machines may function as the intrinsic dynamics of evolution of the information ecology, which involves the property exchanges between them. As a result, the focus of the interface design will shift in some degree to the human side in order to meet their demands of newly technological armors, which marks the re-intelligentization of the human being. In this sense, the intelligent information ecology will be a new battlefield, where human is becoming the commanding height. Thus, how to design the experiment spaces to accommodate such a process will be the critical issue in the first place.

According to Immanuel Kant, we should always treat human beings as an end in itself rather than as a means. In his view, human beings have "an intrinsic worth, i.e., dignity", which makes them valuable "above all price." In the information ecology, such an imperative should always be abided by. Clearly, as far as human being's freedom is concerned, more data, more information, and more knowledge, does not mean more wisdom. Just as Chinese philosopher Lao Tsu's saying, "He who knows the white, yet cleaves to the black, becomes the standard by which all things are tested; And being such a standard, he has all the time a power that never errs. He returns to the limitless"(Lao Tsu, Chapter XXVIII, tr. A. Waley). In this sense, to respect and safeguard human beings' dark world, which means the unknown, reflects true wisdom which is necessary in safeguarding their dignity. Fortunately, there are indeed opportunities to do this, which lies in the new alliance between the people and researchers/companies who want to safeguard humanities rather than to take humanities just as resources.

Conflicts of Interest: The author declares no conflict of interest.

\section{References}

1. Ihde, D. Technology and the Lifeworld: From Garden to Earth; Indiana University Press: Bloomington, IN, USA, 1990.

2. Zhang, B., Wang, D. On phenomenology of artifacts: A new analysis framework. Philos. Res. 1995, 6, 113-119. (In Chinese)

3. Davenport, T.H.; Prusak, L. Information Ecology: Mastering the Information and Knowledge Environment; Oxford University Press: Oxford, UK, 1997.

4. Nardi, B.; O'Day, V. Information Ecologies: Using Technology with Heart; MIT Press: Cambridge, MA, USA, 1999.

5. Wang, X.; Guo, Y.; Yang, M.; Chen, Y.; Zhang, W. Information ecology research: Past, present, and future. Inf. Technol. Manag. 2017, 18, 27-39, doi:10.1007/s10799-015-0219-3.

6. Dreyfus, H.L. What Computers Still Can't Do: A Critique of Artificial Reason; MIT Press: Cambridge, MA, USA, 1992.

7. Hendler, J., Mulvehill, A.M. Social Machines: The Coming Collision of Artificial Intelligence, Social Networking, and Humanity; Apress: New York, NY, USA, 2016.

8. Bostrom, N. Superintelligence: Paths, Dangers, Strategies; Oxford University Press: Oxford, UK, 2014.

(C) 2017 by the author. Licensee MDPI, Basel, Switzerland. This article is an open access article distributed under the terms and conditions of the Creative Commons Attribution (CC BY) license (http://creativecommons.org/licenses/by/4.0/). 